International Journal of Design and Manufacturing Technology (IJDMT)

Volume 9, Issue 1, January-April 2018, pp. 08-16, Article ID: IJDMT_09_01_002

Available online at

http://www.iaeme.com/ijdmt/issues.asp?JType=IJDMT\&VType=9\&IType $=1$

Journal Impact Factor (2018): 6.8970 (Calculated by GISI) www.jifactor.com

ISSN Print: 0976 - 6995 and ISSN Online: 0976 - 7002

DOI: 10.34218/IJDMT.9.1.2018.002

(C) IAEME Publication

\title{
AN EMPIRICAL MODEL OF LOW PLASTICITY BURNISHING TO IMPROVE SURFACE ROUGHNESS AND HARDNESS
}

\author{
A.P. Kalmegh \\ Research Scholar, Department of Mechanical Engineering, \\ Government Engineering College, Amravati, India.

\section{Dr. P.M. Khodke} \\ Principal, Department of Mechanical Engineering, \\ Government Engineering College, Karad, India.
}

\begin{abstract}
The preliminary experimentation and available information indicate that careful setting of burnishing parameters is essential to have better surface finish and surface hardness. This paper presents empirical model of surface roughness $(R a)$ and hardness $(H w)$ for low plasticity burnishing $(L P B 囚)$ process using dimensional analysis. The methodology of selecting the right set of dimensionless group among the different possible combinations, selecting different respective variable groups has been discussed. The constant of (Ra) and $\mathrm{Hw}$ in specialized form of the equation are evaluated from experimental results. The developed empirical models show close agreement with the observed values with correlation coefficient within confidence level. $\angle P B \circledR$ is a registered trademark of Lambda Technologies group.
\end{abstract}

Key words: Dimensional Analysis, LPB®, Surface Roughness, Surface Hardness.

Cite this Article: A.P. Kalmegh and Dr. P.M. Khodke, An Empirical Model of Low Plasticity Burnishing To Improve Surface Roughness and Hardness. International Journal of Design and Manufacturing Technology 9(1), 2018, pp. 8-16. http://www.iaeme.com/ijdmt/issues.asp?JType=IJDMT\&VType=9\&IType=1

\section{INTRODUCTION}

The recent methods reported in literature for mechanical surface treatments of metals includes conventional burnishing, shot peening, laser peening, water peening, liquid peening, etc [1]. The burnishing is simple in tooling, economical and efficient compared to grinding, honing, super finishing and polishing. These surface enhancement methods have shown their applicability with different degree of freedom. Burnishing process has additional advantages such as increased hardness and fatigue life as a result of compressive residual stresses; wear resistance, etc. [2]. Low Plasticity Burnishing( LPB®) differ from other conventional 
burnishing processes such as ball burnishing and roller burnishing in a way that it produces less cold work with higher depth of compression. Some of the surface characteristics which can be improved with LPB are surface finish, micro hardness of the surface, low and high cycle fatigue strength, foreign object damage (FOD) tolerance, corrosion resistance, out of roundness and straightness, wear resistance, etc. [3].

LPB produces minimal cold work which offers greatest resistance to thermal relaxation at elevated temperature. Residual stress distribution can exceed well beyond depth of corrosion pits so as to suppress fatigue cracks initiation and corrosion.

Residual stress and cold work distribution by other surface treatment methods are compared with LPB for 1N718 [4]. Fatigue life of AL 7075-T6 is at least 100 times greater for LPB caused due to reduction in corrosion mechanism [5]. The investigation for IN718, Ti-6Al-4V, 17-4Ph steel have been carried out to find out the relation between percentage of cold work, depth of compressive layers and residual stresses [6]. LPB (for Ti-6Al-4V) is used to improve high cycle fatigue damage tolerance of turbine engine compressor components [7]. The experimental models for surface finish, hardness and fatigue life are developed using factorial design of experiment, considering ball diameter, speed pressure and no, of tool passes as a significant factor for AISI 1045 material [3]. Mathematical model is presented based on Hooke's law and is validated using Taguchi orthogonal array considering speed, part diameter and no. of passes [8]. The experimentation on depth and magnitude of compression and fatigue and damage tolerance has been carried out for turbine blades. The micro cracks are found to be fully arrested by LPB to the depth of $0.75 \mathrm{~mm}$. [9]. All four variables ball diameter, speed, feed, no, of tool passes are found significant for surface roughness and hardness. Surface hardness increases with increase in rolling force $\&$ ball diameter, whereas it decreases with increase in no. of passes and initial roughness. SR improves with increase in ball diameter, feed and burnishing force \& initial roughness [10]. Correlation of surface roughness depends on the work material, as order of significant factors is different for $316 \mathrm{~L} \mathrm{SS}$, Ti-6Al-4V. Experimentation with factorial design and ANNOVA gives relation for surface roughness [11].

For traditional roller and ball burnishing much of the knowledge is available as these methods are studied by the many investigators for different applications. However, a little knowledge is available for LPB process to get its maximum efficiency particularly for steel material. Literature review reveals that more study is required to emphasize the benefits of LPB on steel material, particularly for the steel material which has to sustain high load, high temperature, high corrosion environment, etc. there are some materials which can inherently sustain the above requirement due to their desired material composition. But the cost of these materials may be very high. It is required to introduce all the above properties to get benefits of high cost material with low cost material also. LPB proved its utility to enhance the above surface properties with low cost.

This suggest that semi-empirical model developed form observed data incorporating wide range of input output conditions is a better alternative to understand the process more comprehensively. Since properly recorded data fully incorporates the missing knowledge relevant to the major variables, if physical mechanism of the process is unknown, a systematic quantitative analysis of data should lead us to this missing knowledge. The data gathered through extensive and exhaustive experimentations should lead to establishing generalized comprehensive model of LPB system that explains the behaviour in a very large majority of situations. 


\section{DIMENSIONAL ANALYSIS}

Dimensional analysis offers a method for reducing complex physical problems to the simplest form prior to obtaining a quantitative answer. The principal use of dimensional analysis is to deduce from a study of the dimensions of the variables in any physical system certain limitations on the form of any possible relationship between those variables [12]. The method is of great generality and mathematical simplicity. At the heart of dimensional analysis is the concept of similarity. In physical terms, similarity refers to some equivalence between two things or phenomena that are actually different. Mathematically, similarity refers to a transformation of variables that leads to a reduction in the number of independent variables that specify the problem [13].

\subsection{The steps of dimensional analysis}

The premise of dimensional analysis is that the form of any physically significant equation must be such that the relationship between the actual physical quantities remains valid independent the magnitudes of the base units [14].

\section{Step 1: The independent variables}

The first and most important step in dimensional analysis is to identify a complete set of independent quantities $Q 1 \ldots Q n$ that determine the value of $Q 0$ [12],

$\mathrm{Q} 0=\mathrm{f}(\mathrm{Q} 1, \mathrm{Q} 2, \ldots, \mathrm{Qn})$

\section{Step 2: Dimensional considerations}

Next we list the dimensions of the dependent variable $Q O$ and the independent variables $Q 1 \ldots . . Q n$. we must specify at least the type the system of units before we do this. For example, if we are dealing with a purely mechanical problem, all quantities have dimensions of the form

$\left[\mathrm{Q}_{\mathrm{i}}\right]=\mathrm{L}^{\mathrm{li}} \mathrm{M}^{\mathrm{mi}} \mathrm{t}^{\mathrm{\tau i}}$

where the exponents $l i, m i$ and $\tau i$ are dimensionless numbers that follow from each quantity's definition.

\section{Step 3: formation of dimensionless $\pi$ terms}

If there are $n$ numbers of variables and $m$ fundamental dimensions are included then $n-m$ is the number of dimensionless $\pi$ terms [15]. In order to form these $\pi$ terms, there is need to choose repeating variables. These variables should be such that:-

a) None of them should be dimensionless,

b) No two variables have the same dimensions,

c) They themselves do not form a dimensionless parameter, and

d) All the fundamental dimensions are included collectively in them.

e) as far as possible, dependent variable should not be a repeating variable.

Moreover, as far as possible, the dependent variable should not be taken as a repeating variable as otherwise it will not be possible to obtain an explicit relationship. $\pi$ term is a combination of ' $\mathrm{m}$ ' repeating variables with one non repeating variable. The relationship between the dependent variable then can be given as:

$\pi_{1}=\mathrm{f}\left(\pi_{2}, \pi_{3}, \ldots \ldots \pi_{\mathrm{n}-\mathrm{m}}\right)$. 


\section{VARIABLE SELECTION}

Preliminary experimentation and technical literature indicated that the increase in hardness in LPB process depends on ball diameter, pressure, speed, initial surface roughness. Whereas as feed, hardness of ball and viscosity of lubricant are not significant. The independent factors considerate to be of principle importance, identified by trial investigation are shown in table 1 .

In this case, for surface hardness using LPB, following parameters can be considered for analysis.

Table 1 Variables, Types, Symbol, with their units and dimensions

\begin{tabular}{|c|c|c|c|c|c|}
\hline $\begin{array}{c}\text { Sr. } \\
\text { no. }\end{array}$ & Variables & Type of variable & Symbol & Unit & Dimension \\
\hline 1 & Surface roughness & Dependent & $\mathrm{R}_{\mathrm{a}}$ & $\mu \mathrm{m}$ & $\mathrm{L}^{1}$ \\
\hline 2 & Ball diameter & Independent & $\mathrm{D}$ & $\mathrm{Mm}$ & $\mathrm{L}^{1}$ \\
\hline 3 & Pressure & Independent & $\mathrm{P}$ & $\mathrm{N} / \mathrm{mm}^{2}$ & $\mathrm{M}^{1} \mathrm{~L}^{-1} \mathrm{~T}^{-2}$ \\
\hline 4 & Speed & Independent & $\mathrm{S}$ & $\mathrm{Rpm}$ & $\mathrm{T}^{-1}$ \\
\hline 5 & Initial surface roughness & Independent & $\mathrm{R}_{\mathrm{ai}}$ & $\mu \mathrm{m}$ & $\mathrm{L}^{1}$ \\
\hline
\end{tabular}

\subsection{Selection of Repeating Variables}

There are total 5 variables included therefore $n=5 \mathrm{M}, \mathrm{L}$ and $\mathrm{T}$ are the fundamental dimensions. Hence $m=3$. So there will be $m=3$ repeating variables and $n-m=2 \pi$ terms.

Applying the set of rules (section 2.1, steps 3 ) to choose repeating variables, pressure, speed and ball diameter can be considered best suit for the consideration. So the 2 dimensionless $\pi$ terms formed by the combination of three repeating and one non repeating variable are listed in table 2 .

Table 2 list of $\pi$ terms and repeating and non repeating variables involved in them.

\begin{tabular}{|c|c|c|c|}
\hline Sr.No. & $\pi$ term & $\begin{array}{c}\text { Repeating } \\
\text { variables }\end{array}$ & Non repeating variable. \\
\hline$\pi_{1}$ & $\mathrm{P}^{\mathrm{a} 1} \mathrm{~S}^{\mathrm{b} 1} \mathrm{D}^{\mathrm{c}} \mathrm{R}_{\mathrm{a}}$ & \multirow{2}{*}{$\mathrm{P}, \mathrm{S}, \mathrm{D}$} & $\mathrm{R}_{\mathrm{a}}$ \\
& $\mathrm{P}^{\mathrm{a} 2} \mathrm{~S}^{\mathrm{b} 2} \mathrm{D}^{\mathrm{c} 2} \mathrm{R}_{\mathrm{ai}}$ & & $\mathrm{Rai}$ \\
\hline
\end{tabular}

\subsection{Construction of dimensionless group}

The constants a1, b1, c1, from term $\pi_{1}, a 2, b 2$, c2, from $\pi_{2}$, can be found out by equating the powers of individual dimensions to zero. For example,

$\pi_{1=} \mathrm{P}^{\mathrm{a} 1} \mathrm{~S}^{\mathrm{b} 1} \mathrm{D}^{\mathrm{c} 1} \mathrm{R}_{\mathrm{a}}$

Expressing $\pi_{1}$ in dimensions,

$\pi_{1}=\left[\mathrm{M}^{1} \mathrm{~L}^{-1} \mathrm{~T}^{-2}\right]^{\mathrm{a} 1}\left[\mathrm{~T}^{-1}\right]^{\mathrm{b} 1}[\mathrm{~L}]^{\mathrm{c} 1}\left[\mathrm{~L}^{1}\right]$

$\pi_{1=} \mathrm{M}^{(\mathrm{a} 1)} \mathrm{L}^{(-\mathrm{a} 1+\mathrm{c} 1+1)} \mathrm{T}^{(-2 \mathrm{a} 1-\mathrm{b} 1)}$

$\pi_{1}$ is dimensionless term, so dimensions for $\pi_{1}$ are $\mathrm{M}^{0} \mathrm{~L}^{0} \mathrm{~T}^{0}$.

$M^{0} L^{0} T^{0}=M^{(a 1)} L^{(-a 1+c 1+1)} T^{(-2 a 1-b 1)}$

Equating the powers of $\pi_{1}$ and variables of $\pi_{1}$,

a1 $=0$

$-\mathrm{a} 1+\mathrm{c} 1+1=0$

$-2 \mathrm{a} 1-\mathrm{b} 1=0$ 
Solving the above equations (2),(3),(4) simultaneously, we get,

$\mathrm{a} 1=0$

$\mathrm{b} 1=0$

$\mathrm{c} 1=-1$

Substituting the values in equation (1),

$\pi_{1=} \mathrm{P}^{-1} \mathrm{~S}^{0} \mathrm{D}^{0} \mathrm{R}_{\mathrm{a}}$

$\pi_{1=}\left(\mathrm{R}_{\mathrm{a}}\right) / \mathrm{D}$

Similarly, other $\pi$ terms can be found out. The all $2 \pi$-terms with their description are listed in the table 3.

Table 3 Description of Dimensionless group

\begin{tabular}{|c|c|c|c|}
\hline Sr. No. & $\boldsymbol{\pi}$ term & Term name & Physical meaning \\
\hline$\pi_{1}$ & $\mathrm{R}_{\mathrm{a}} / \mathrm{D}$ & Surface finish number & $\begin{array}{c}\text { This will represent the amount of asperities } \\
\text { smoothened to decrease the roughness and } \\
\text { improve surface finish. }\end{array}$ \\
\hline$\pi_{2}$ & Rai/D & $\begin{array}{c}\text { Initial surface roughness } \\
\text { number }\end{array}$ & $\begin{array}{c}\text { Relative measure of intial surface roughness } \\
\text { on final surface roughness. }\end{array}$ \\
\hline
\end{tabular}

Application of dimensional analysis to the variables in table 1 with the combination of repeating variables as discussed above leads to the surface roughness equation representing the relationship between variables in terms of dimensionless ratios as,

$\frac{\mathrm{Ra}}{\mathrm{D}}=\left(\frac{\mathrm{Rai}^{\mathrm{a}}}{\mathrm{D}}\right)$

$(\pi 1)(\pi 2)$

Groups denoted by $\pi 2$ are independent while $\pi 1$ is dependent group. The dimensionless groups given in above equation have physical meaning as given in table 3 , and therefore are suitable for experimental planning.

\subsection{Test envelope}

The test envelope for each of the above dimensionless group has been determined by conducting separate single factor experiments for AISI4340 material and the test points have been decided on the basis of zone of significance of the variable. The chosen values of the variables for experiments and corresponding confidence level and accuracy of measurement are depicted in the table 4.

Table 4 Test envelope and test points

\begin{tabular}{|c|c|c|c|c|}
\hline $\begin{array}{c}\text { Dimensionless } \\
\text { Ratio }\end{array}$ & $\begin{array}{c}\text { Independent } \\
\text { variable }\end{array}$ & $\begin{array}{c}\text { Test } \\
\text { envelope }\end{array}$ & $\begin{array}{c}\text { Test points and } \\
\text { their sequence }\end{array}$ & $\begin{array}{c}\text { Measurement of } \\
\text { Accuracy }\end{array}$ \\
\hline$\pi 2=($ Rai $) / D$ & Rai & 3 to $7(\mu \mathrm{m})$ & $3,6,4,7,5$ & 0.001 \\
\hline
\end{tabular}

\section{EXPERIMENTATION}

In LPB system, the ball is pressurized against rotating work piece. The oil/tool coolant is used to pressurize the bearing, with continuous flow of fluid to support the ball. The ball does not contact the mechanical bearing seat, even under load. The ball is loaded at a normal force to 
the surface of a component, with a hydraulic cylinder that is in the body of tool. A set up of newly developed LPB tool is shown in Fig.1.

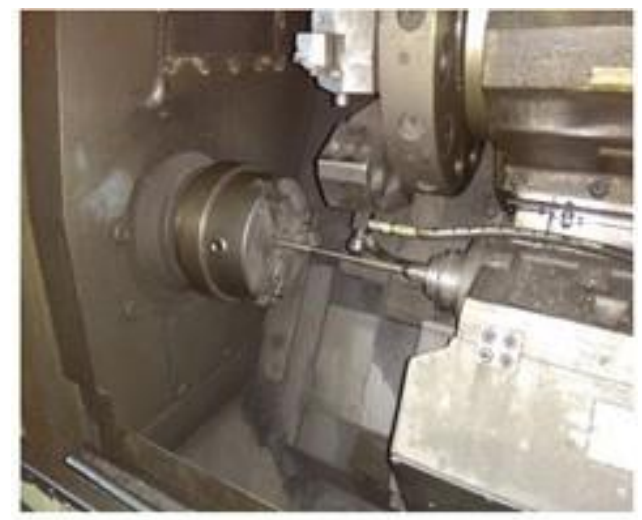

Figure 1 Experimental set up

Table 5 Effect of $\pi_{2}$ on $\pi_{1}$

\begin{tabular}{|c|c|c|c|c|c|}
\hline Initial SR (Rai) $\mu \mathrm{m}$ & 3 & 4 & 5 & 6 & 7 \\
\hline Final SR $(\mathrm{Ra}) \mu \mathrm{m}$ & 0.445 & 0.754 & 0.976 & 1.326 & 1.886 \\
\hline
\end{tabular}

\section{DETERMINATION OF EQUATION CONSTANT:}

For evaluating the exponents of the different dimensionless group reflected in equation (6), polynomial relationship $\mathrm{Y}=\mathrm{C}_{\mathrm{n}} * \mathrm{X}^{\mathrm{m}}$ was assumed [13]. Here, $\mathrm{C}_{\mathrm{n}}$ is the proportionality constant and $\mathrm{m}$ is the exponent associated with the variable $\mathrm{X}$. Then after log conversion,

$\log \mathrm{Y}=\log \mathrm{C}_{\mathrm{n}}+\mathrm{m}^{*} \log \mathrm{X}$

The value of $\mathrm{C}_{\mathrm{n}}$ and $\mathrm{m}$ for every dimensional group were obtained using the method of least squares by taking the observed data tabulate in table 5 . The values of exponents thus obtained for these groups are presented in table 6 .

Table 6 Values of exponents for dimensionless group.

\begin{tabular}{|c|c|}
\hline Group & $\pi_{2}$ \\
\hline Exponent & 0.899 \\
\hline
\end{tabular}

On substitution of these exponents in equation (6) and subsequent transformation, the model for surface roughness can be written as,

$\mathrm{Ra}=\mathrm{A}\left(\mathrm{D}^{0.101} \mathrm{Rai}^{0.899}\right)$

The constant A was evaluated by substituting values of variables and was found equal to 0.3806 .

The characteristic variation of surface roughness, obtained from the model is graphically shown in Fig 2. 


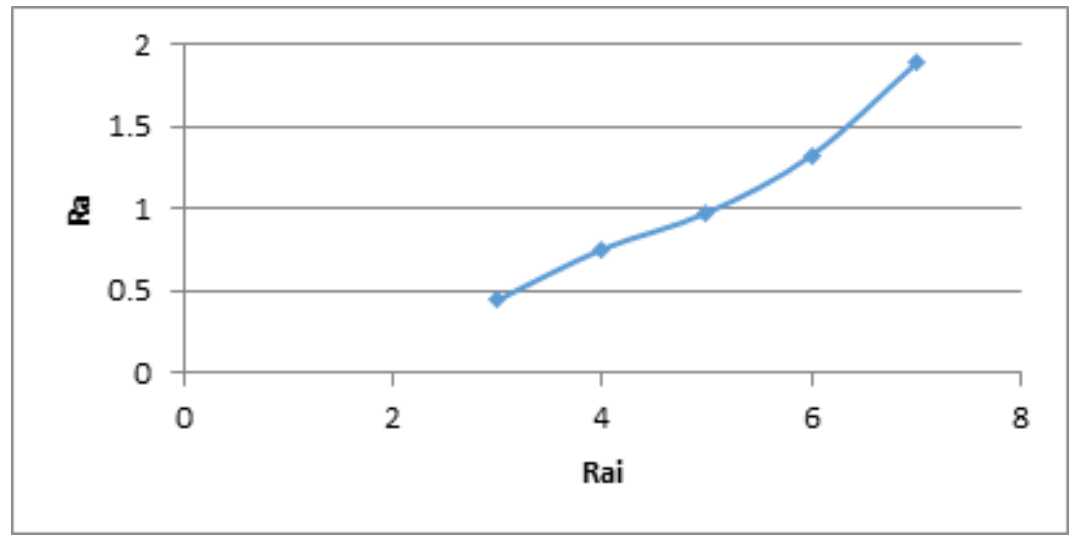

Figure 2 Characteristic effect of initial surface roughness on final surface roughness

The observed and predicted values of surface roughness are shown in Fig. 3 and it has been found that the correlation between them is 0.9424

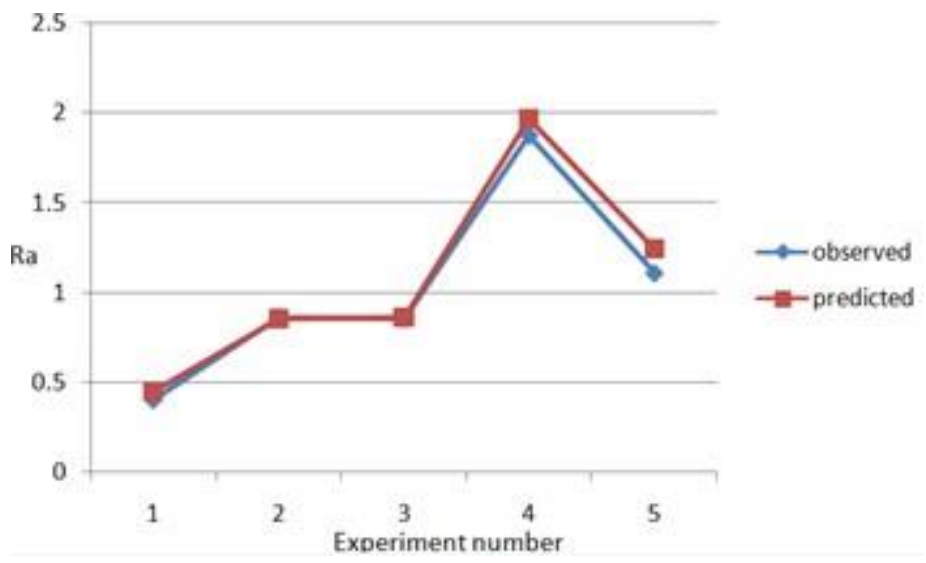

Figure 3 Observed and predicted values of surface roughness

Similarly, an empirical model is developed for surface hardness, is as follows:

$\mathrm{H}_{\mathrm{w}}=\mathrm{B}\left(\mathrm{P}(\mathrm{BD})^{-0.67} \mathrm{Rai}^{0.67}\right)$

The constant $\mathrm{B}$ was evaluated by substituting values of variables and was found equal to 1511.7149 .

The observed and predicted values of Surface hardness are shown in fig. 4 and it has been found that the correlation between them is 0.9767 .

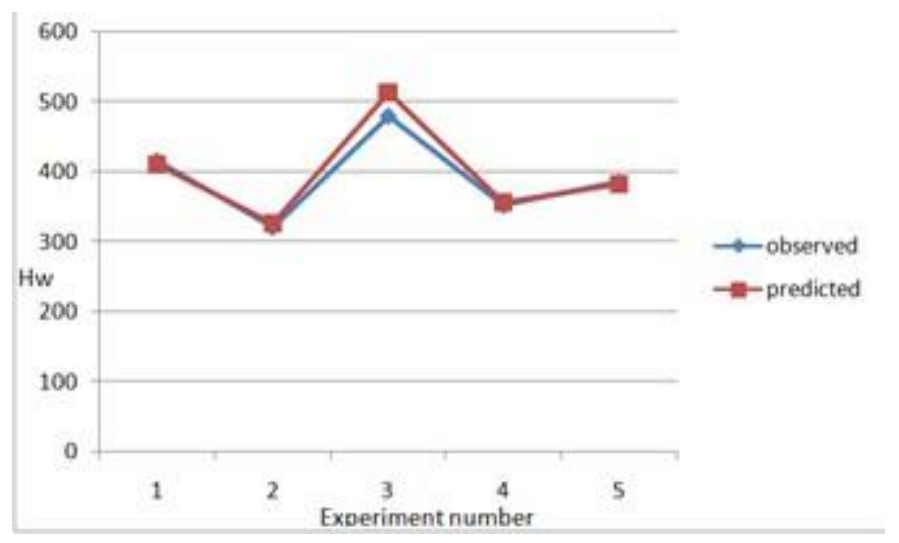

Figure 4 observed and predicted values of surface hardness 


\section{CONCLUSION}

- The semi empirical model represented by equation (7) is complete description of surface roughness. It gives clear idea how ball diameter, initial surface roughness affect on response surface roughness.

- Ball diameter and initial surface have positive effect on surface roughness.

- The semi empirical model represented by equation (8) shows how ball diameter, initial surface roughness and pressure affect on surface hardness.

- Surface hardness increases with increase in pressure, initial surface roughness and decrease in ball diameter.

- The correlations between the observed and predicted value of surface roughness and surface hardness have been found to be 0.9424 and 0.9767 respectively.

\section{REFERENCES}

[1] A. P. Kalmegh, P. M. Khodke, D. S. Mankar "An Overview of Alternative Mechanical Surface Treatments", International Journal of Engineering Trends and Technology (IJETT) - Volume X Issue Y- Month 2015 ISSN: 2231 5381http://www.ijettjournal.org

[2] M.M. EL-Khabeery , M.H.EL-Axir, 'Experimental techniques for studying the effects of milling roller-burnishing parameters on surface integrity', International Journal of machine tools and manufacture 41,2001, 1705-1719.

[3] C.Y.Seemikeri, P.K.Brahmankar, S.B.Mahagaonkar, 'Investigation on surface integrity of AISI 1045 using LPB tool', Tribology International 41, 2008, page724-734.

[4] Paul S.Prevey, John T. Cammett, 'The Influence of surface enhancement by low plasticity burnishing on the corrosion fatigue performance of AA7075-T6', International Journal of Fatigue 26, 2004, page975-982.

[5] Paul S.Prevey, Ravi A.Ravindranath, 'Paul S.Prevey, Lambda Research, Cincinnati, OH, 'The effect of cold work on the thermal stability of residual compression in surface Enhanced IN718', 20th ASM Materials Solution Conferences \& Exposition St.Louis , Missouri, october 10-12,2000.

[6] Paul S.Prevey, Ravi A.Ravindranath, Case studies of fatigue life improvement using low plasticity burnishing in gas', Journal of engineering for gas turbines \& power, Vol.128/865 October 2006.

[7] Paul S.Prevey, N.Jayaraman ,Ravi A.Ravindranath, Michael Shepard, 'Improved high cycle fatigue damage tolerance of turbine- engine compressor components by low plasticity burnishing', Journal of engineering for gas turbines \& power, Vol.130/012102- 1, January 2008 .

[8] Petru Dusa \& Gabriel Dumitriu, 'Analytical method of residual stress evolution into superficial layers at low plasticity burnishing (LPB)', international Journal of Materials Processing Technology ISSN 2067-3604, Vol.1,No.1/2009.

[9] Paul S.Prevey, N.Jayaraman, Ravi A.Ravindranath, Michael Shepard, 'Mitigation of fretting fatigue damage in blade and desk pressure faces with low plasticity burnishing (LPB)', Vol.132/082105-1, August 2010.

[10] P.R.Prabhu, S.M.Kulkarni, S.S.Sharma, 'Influence of deep cold rolling and low plasticity burnishing on surface hardness and surface roughness of AISI 4140 Steel', World Academy of Science, Engineering and Technology $72,2010$. 
[11] U.D.Gulhane, S.B.Mishra, P.K.Mishra, 'Enhancement of surface roughness of 316L stainless steel and TI-6AL-4V using low plasticity burnishing: DOE approach', Intyernational journal Mechanical Engineering \& Technology, Vol.3, Issue 1, JanuaryApril2012, PP.150-160.

[12] Ain A. Sonin, “The Physical Basis of Dimensional Analysis", Department Of Mechanical EngineeringMIT, Cambridge, MA 02139, 2001.

[13] P.M. Khodke and D. J. Tidke, "An empirical model of material removal in Abrasive Jet machining”, Advances in Mechanical Engineering, 1996, Pp. 723-737

[14] Bachchhav B.D, Lathkar G.S., Reddy Y P and Bagchi H "Wear under lubricated sliding contacts-A Dimensional analysis model", Journal of manufacturing engineering, Sept. 2013, vol. 8, issue 3, pp 139-144.

[15] Buckingham's $\pi$ Theorem And Dimensional Analysis With Examples, Noah J. Cowan, 2010 